\title{
An Advanced Fusion Energy System for Outer-Planet Space Propulsion
}

\section{by Robert W. Bussard, Ph.D., Energy/Matter Conversion Corporation, 680 Garcia Street, Santa Fe, NM 87505, <emc2qed@comcast.net>}

\section{Abstract}

Inertial-electrostatic-fusion (IEF) devices using polyhedral magnetic fields for electrostatic potential well confinement of ions offer light-weight sources of large thermal and electrical power from clean $\mathrm{p}+{ }^{\mathrm{II}} \mathrm{B}$ fusion reactions. Application to direct heating offers propulsion system thrust/mass ratios IOO-IOOOx larger than other advanced concepts in the specific impulse range of $1500<I_{s p}<\mathrm{I} .2 \mathrm{E} 6 \mathrm{sec}$. Review of engineering interface limits and constraints of these fusion sources shows that no new and unconventional technologies are needed for their achievement Analysis of an outer-planet mission to Titan (Saturn's large moon) with diluted-fusion-product (DFF) propellant heating engine systems shows singlestage vehicles with payload delivery fractions of O.I4-0.I8 of gross launch mass, with transit times of only $\mathrm{II}^{-} \mathrm{I} 3$ weeks. Economic models of development and deployment of such vehicles suggest that practical, rapid space flight and colonization could be achieved within present budget limits.

\section{Nomenclature}

$a_{0} \quad=$ initial vehicle force acceleration, $\left(\mathrm{m} / \mathrm{s}^{2}\right)$

$a_{f} \quad=$ final vehicle force acceleration, $\left(\mathrm{m} / \mathrm{s}^{2}\right)$

$\mathrm{AU}=$ astronomical unit, distance from $\mathrm{E}$ to Sun

$B \quad=$ magnetic field strength, (Tesla)

$C_{o} \quad=$ total cost over mission life, $\mathrm{Y},(\$)$

$\mathrm{E}=$ Earth

$E_{0} \quad=$ core energy in IEF system, $(\mathrm{eV})$

$F \quad=$ engine thrust, $(\mathrm{N})$

$[F] \quad=$ engine system thrust $/$ mass ratio

$f_{L} \quad=$ payload fraction of gross mass

$G_{\text {gross }} \quad=$ ratio gross fusion to electric drive power

$g_{o} \quad=$ acceleration of gravity at Earth's surface

$I_{s p} \quad=$ engine system specific impulse, (s)
LEO = Low Earth (satellite) Orbit

LTO = Low Titan (satellite) Orbit

$m_{e} \quad=$ engine system mass, $(\mathrm{kg})$

$m_{0} \quad=$ vehicle gross mass, $(\mathrm{kg})$

$m_{L} \quad=$ payload mass, $(\mathrm{kg})$

$m_{p} \quad=$ propellant mass, $(\mathrm{kg})$

$P_{f} \quad=$ gross fusion power, $(\mathrm{MW})$

$P_{e}, P_{n e t}=$ net fusion or electric power, (MW)

$S_{b} \quad=$ incremental distance traversed over $t_{b}(\mathrm{~m})$

$t_{b} \quad=$ engine thrusting ("burn") time, (s)

$\mathrm{T}=$ surface of Saturn's moon, Titan

$v \quad=$ vehicle speed,$(\mathrm{m} / \mathrm{s})$

$v_{e}=g f_{s p}=$ propellant exhaust speed, $(\mathrm{m} / \mathrm{s})$

$\delta v_{c}=$ "characteristic" velocity of flight, $(\mathrm{m} / \mathrm{s})$

$\mathrm{Y} \quad=$ mission time, (years)

\section{Introduction}

Practical space flight requires rapid transits and high payload fractions in single-stage vehicles. This is possible only with propulsion systems of very large specific impulse $\left(I_{s p}\right)$ and high engine system thrust-to-mass ratio $[F]$. With high [F], gravity "losses" in g-field-climbing will be minimal; with concurrent high $I_{s p}$ very high characteristic velocities $\delta V_{c}$ needed for rapid transits can be achieved as well ${ }^{2}$. The energy available from chemical reactions limits rocket payload fractions $f_{L}$ to small values for most interesting space missions, even with multiple staging. And no chemical vehicle system is capable of rapid (e.g. less than one year) interplanetary flight.

The engines needed must have super-energetic performance and no massive structures. Nuclear fission propulsion systems can not meet these requirements 33.4 . These can be achieved only with non-radiative nuclear fusion reactions that do not require massive shielding, and that yield only energetic charged particles 
The reaction of interest is that between $\mathrm{p}(\mathrm{I} \mathrm{H})$ and ${ }^{\mathrm{II}} \mathrm{B}$. These can be "burned" in special inertial-electrostaticfusion (IEF) devices 5,6 which trap energetic electrons in quasi-spherical polyhedral magnetic fields to produce a negative potential well that confines the fusion ions. Such IEF power sources yield energetic $(\mathrm{MeV})$ charged fusion products (alpha particles). These can be trapped in toroidal magnetic fields around the source, and made to heat a propellant-diluent by inter-particle collision. Such a diluted-fusion-product (DFP) engine system avoids the difficulties and thermal limitations of energy conversion and allows attainment of extremely high specific impulse (5E4-I.2E6 sec), best suited for outer planet missions in the solar system. The variation of $I_{s p}$ with $[F]$ is shown in Figure I, for these and other concepts of "advanced" fusion propulsion 7 , including direct-electric quiet-electric-discharge (QED) engines based on IEF use. Details of these other engine systems, their components and subsystems, layout, mass breakdown and performance have been given in previous studies ${ }^{8,9,10}$.

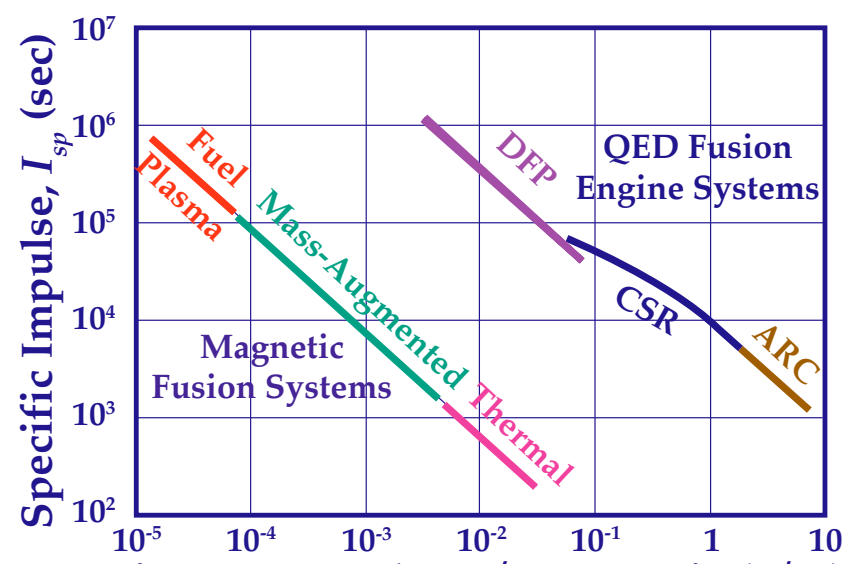

Engine System Thrust/Mass Ratio (F/M)

Figure $1-I_{s p}$ vs. [ $F$ for QED(ARC/CSR), DFP and Other "Advanced" Space Propulsion System Concepts

This paper presents a discussion of engineering issues involved in the DFP engine subsystems and system concept, and of the performance potential of such systems. This is shown in one example mission of colonization of Saturn's large moon, Titan, assuming launching from LEO and rapid transit to and from orbit around Titan (LTO). The economic results cited are based on cost estimates for several space colonization transport missions, using QED and DFP engines, presented in detail in earlier work ${ }^{\mathrm{r}, \mathrm{II},{ }^{2}}$. Detailed economic and performance models were used to show the costs of transport, establishment and maintenance of human colonies on Luna (the Moon), Mars, and Titan, the large inner moon of Saturn. Payload transport costs were determined, based on various assumptions of the costs of system development, manufacture and use. Economics and costs cited here are taken from these earlier studies.

\section{IEF Power Sources}

The IEF fusion-electric source systems of interest here all use quasi-spherically-symmetric polyhedral magnetic fields to confine electrons which are injected at high energy $E_{o}$, so as to form a negative electric potential well that can confine fusion ions in spherically-converging flow. Figure 2 shows a schematic diagram of this electron-acceleration (EXL) IEF system. Fusion ions are inserted into the well near its boundary $R$, so that they "fall" towards the center and oscillate across the machine, with density increasing rapidly $\left(\mathrm{I} / r^{2}\right)$ towards the center. Typical ion convergence ratios $\left\langle r_{c}\right\rangle=r_{c} / R$ are O.OOI $\left\langle\left\langle r_{c}\right\rangle<0.01\right.$, which yield core densification of $\mathrm{IE}_{4}$-IE6 above the minimum ion densities in the system Their injection rate is controlled relative to electron drive current so that their core energy is held at the design value desired for the fusion reaction process in the system.

\section{EXL - Electron Acceleration}

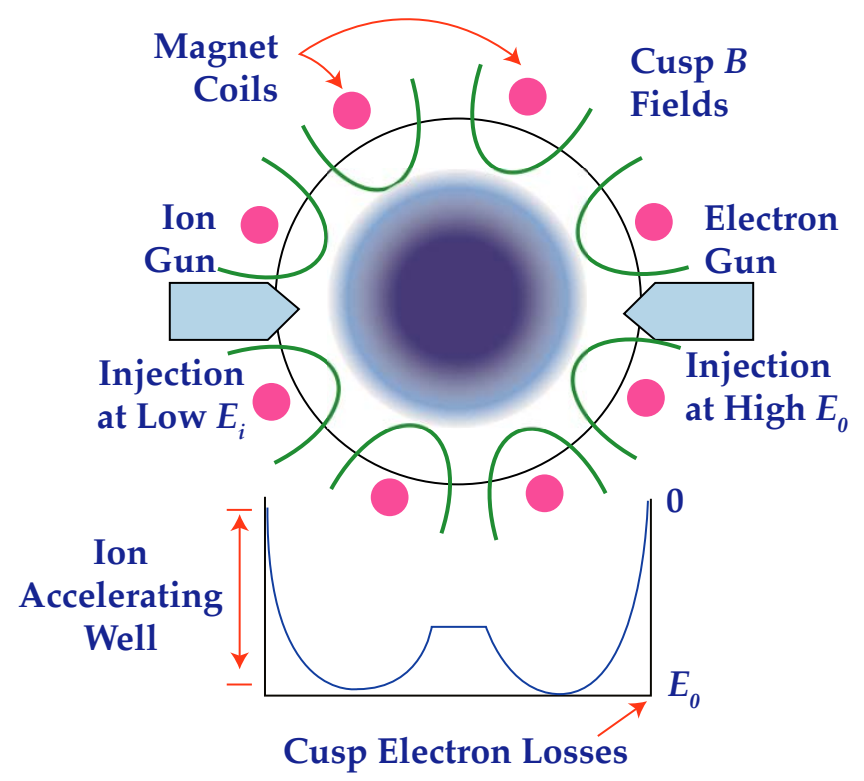

Figure 2 - EXL/IEF Concept; Ion Acceleration by Electron-Driven Negative Potential Well in Polyhedral Magnetic Fields

\section{Clean Fusion Reactions}

Fusion reactions whose products consist solely of charged particles are free from the radiation hazards of energetic neutrons which always characterize fusion in deuteron-bearing mixtures. The clean fusion fuel com- $^{-}$ bination of interest here is $\mathrm{p}(\mathrm{I} H)$ and ${ }^{\mathrm{I}} \mathrm{B}$, which reacts according to $\mathrm{p}+{ }^{\mathrm{II}} \mathrm{B}->34 \mathrm{He}$, with energy release of 8.68 $\mathrm{MeV}$ split between the three alpha particles that are the fusion products (fp). The direct production of electric power from these reactions is possible by deceleration of the charged fp ions in an externally-imposed electric field. They will move predominantly radially from their 
central birth point in the IEF core region, and can be collected as they approach zero kinetic energy, by grids or plates placed at appropriate radial positions along the particle path. These collectors are connected to the electrical circuit in which current is driven through the system external load, and are biased so as to slow down the alphas and convert their kinetic energy into electrical energy in the external circuit. The fusion products of $\mathrm{p}+{ }^{\mathrm{II}} \mathrm{B}$ have one alpha with a fixed energy of $3.76 \mathrm{MeV}$ and the other two with an energy spread from $74 \mathrm{keV}$ to $4.846 \mathrm{MeV}$, peaking strongly around $3.76 \mathrm{MeV}$. The actual voltages across the decelerating grids of the direct convertor system (DCS) will be less than these values ${ }^{12}$ because the alphas have a charge of $Z=2$, and the escaping fps give up energy to the confining negative potential well, before reaching the DCS region. Typically this may be $180 \mathrm{keV}$, which then reduces the actual grid voltage range to $0.44^{-2.24} \mathrm{MV}$ at the outermost grid/plate. To stay within conservative voltage gradients, a complete $\mathrm{p}$ + ${ }^{\mathrm{I} B}$ DCS system needs only about $\mathrm{I} 2$ grids over $\mathrm{I} 2 \mathrm{O} \mathrm{cm}$ outside the IEF region required for the controlled fusion process, itself. In the DFP engine system, a radial distance of nearly $5 \mathrm{~m}$ is available (see later discussion) so that the inter-grid voltage gradients can be kept at a low value of only $3.6 \mathrm{kV} / \mathrm{cm}$.

\section{IEF Vacuum System Operation and Fuel Recycling}

In conventional applications, IEF sources must be maintained and operated at low background pressure $\left(<\mathrm{IE}^{-} 7\right.$ torr) by continuous vacuum pumping within the outer shell containing both the IEF reaction region and the external region in which electrons and ions recirculate. This will remove both unburned fuel atoms as well as the fusion products, themselves, which must then be separated for subsequent use.

However, in the DFP engine concept the fusion products must escape the IEF source into an external region to heat the propellant/diluent injected into this region, while the unburned fuel ions must be trapped and returned to the IEF system, to avoid unacceptable fuel losses. System thrust level and specific impulse are determined by control of the mixture ratio of diluent and fusion product mass flows in this external region. The IEF system is bounded by its magnetic coils, insulated from electron impact losses by their self-fields. This "magnetic grid" (MG) arrangement allows re-circulation of electrons (but not ions) from the IEF region, into the external propellant -diluent mixing region which, itself, is open to space as its main vacuum pumping system. A simple method exists to capture and reuse unburned fuel before it reaches the mixing region, by use of ionabsorbing "limiters" placed just inside the IEF outer boundary so as to intercept fuel ions that have been upscattered, which would otherwise leave the IEF for the external mixing region. Vacuum pumping of the limiters will then extract the captured fuel ions - now neutral atoms - and allow them to be recycled back into the IEF system. Design studies show that this will not impose a significant power loss on the system by use of this IEF/MG device geometry and limiters.

\section{DFP Engine Systems}

In the DFP engine application, the IEF magnet coils define the active radial boundary $(R)$ of the source, and are its main structure. In a truncated cube geometry, the electron injectors are mounted at $\mathrm{I} . \mathrm{I} 5 \mathrm{R}$ on radial rods extending in from the DFP engine system external confinement/thrust shell. The IEF magnet coils are held in place by mutual interconnects and are supported from the external shell at opposite polar axis locations, surrounding the dual polar DCS units. These supporting struts also carry the electric current from the DCS to drive the magnets, and the support cylinders that supply the $\mathrm{p}^{\mathrm{II} B}$ fuel to neutral gas sources that feed the IEF system. Only a very small fraction of the fusion power need be converted to electricity, thus the DCS needed will occupy only a small solid angle at opposite poles of the IEF device.. For this engine, the gross gain of the fusion power system is in the range of $G_{\text {gross }}=4^{2-} 48$, thus the electric drive power needed is less than $2.5 \%$ of the fusion power produced. The bulk of the fusion product alphas are used to heat the propellant/diluent directly upon their escape from the IEF region. 


\section{Configuration, Thermal Loads and Performance}

The general arrangement of the IEF unit, the DCS and the external confinement/thrust shell in the DFP engine is shown in Figure 3.

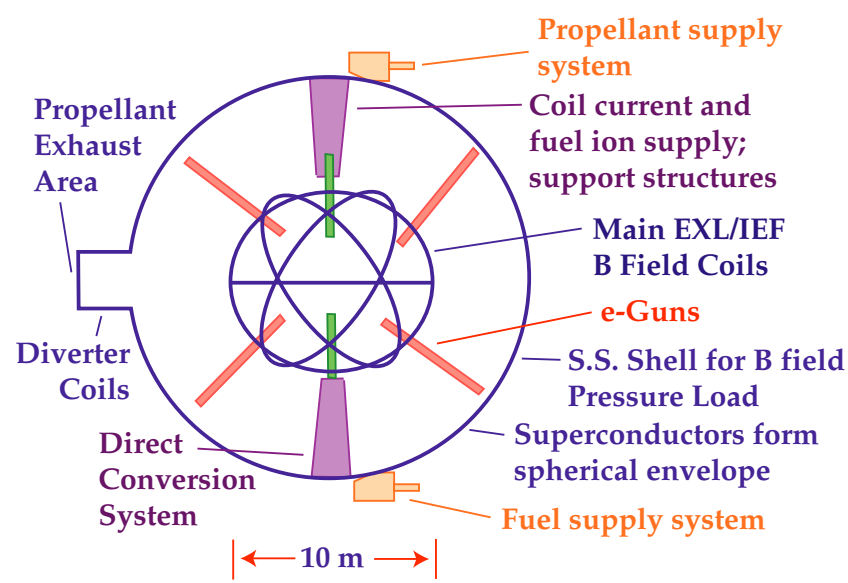

Figure 3 - Schematic Outline of DFP Engine, Showing IEF Placement, Confinement / Thrust Shell, and Magnetic Diverter Exhaust "Nozzle" - Thrust is to the Right

The only unavoidable waste heat that must be removed is that from the magnet coil containers, the electron injection guns, the DCS decelerating grids, and the external thrust shell that "sees" bremsstrahlung from core electrons. The main thermal power load on the magnets, the e-guns, and the DCS grids is that from impact by escaping fusion product ions. Core bremsstrahlung is very much less than the power load from these fusion products. The DCS heating is limited to fusion product ions with residual energy left after direct conversion has taken place.

Detailed analyses have been made ${ }^{\mathrm{II}, \mathrm{I2}}$ of all the relevant thermal loads on each of the DFP engine system structures. These were based on IEF fusion output performance derived from complex computer calculations made using the newly-developed power balance code, QBAL, a MG-inclusive derivative of the earlier PBAL code, which was limited to Wiffle-Ball loss estimation with MG transport losses ignored. Heat loads and output performance were determined from design studies of the gross fusion power, net power output, gain, drive power, bremsstrahlung, and MG transport loss power required for a range of IEF sources for DFP engine systems.

Design studies for DFF engine systems used an IEF source with a fusion-ion-confining radius of $R=5.0 \mathrm{~m}$, driven by electron injection at $220 \mathrm{KeV}$ and operated with an ion convergence ratio of $\left\langle r_{c}\right\rangle=\mathrm{IE}^{-} 3$ with a $B$ field of $\mathrm{I} 3.5 \mathrm{kG}$ at $R$ provided by superconducting magnets. For these design parameters, the IEF device would yield gross fusion power of $P_{f u s}=$ I0,245 MW with a gross power gain $\left(P_{\text {fus }} / P_{\text {drive }}\right)$ of $G_{g r}=46.3$. This gives an elec- tron drive power (the sum of e-gun injector losses, bremsstrahlung and MG transport losses) of $P_{\text {drive }}=22 \mathrm{I}$ MWe. Assume that the grid structures of the DCS subtend 0.05 of the DCS surface as viewed from the IEF core, and allow $70 \mathrm{KeV}$ spread in the convertor deceleration process for a deceleration conversion efficiency of 0.95 . Then, the complete conversion efficiency of the DCS will be 0.90. The remaining o.Io of unconverted power into the DCS must be radiated as waste heat. Since 22I MWe is needed to drive the machine, the DeS must accept a fusion power of $245 \mathrm{MW}$ fus For use of dual, oppositely mounted DCS systems, this requires a DCS acceptance solid angle fraction of O.OI2, which is obtained through a $2.19 \mathrm{~m}$ radius hole at the external shell radius at Io $\mathrm{m}$ from the IEF core center. The total waste heat load is also this $245 \mathrm{MWth}$ (drive and DCS waste heat), which must be dumped to space through a waste heat radiator

With full waste heat space radiation, system performance is limited only by the maximum propellant specific impulse of fusion product alpha particles from $\mathrm{p}^{\mathrm{II}} \mathrm{B}$ fusion. These leave with speeds of $2.2^{-2} .7 \mathrm{E} 9 \mathrm{~cm} / \mathrm{sec}$ for a particle-weighted average speed of $2.4 \mathrm{E} 9 \mathrm{~cm} / \mathrm{sec}$ (o. o8c). Averaging over an angular distribution characteristic of a diffuse emitter, the average effective specific impulse of the propellant/diluent would be $I_{s p}=\mathrm{I} .2 \mathrm{E} 6 \mathrm{sec}$. Lower $I_{s p}$ results from mixing fusion alphas with diluent atoms/ions. The net effective $I_{s p}$ of the mixture is given simply by $I_{s p m i x}=I_{s p o}(\mathrm{I}+D)^{\circ .5}$ where $I_{s p o}$ is the undiluted specific impulse (I.2E6 sec, above) and $D$ is the diluent mass flow ratio. For example, if the diluent mass flow rate is taken as three times that of the fusion fuels, then the resulting specific impulse will be one-half of $I_{s p o}$. At large dilution ratios the $I_{s p}$ varies as $\mathrm{I} / D^{\circ .5}$, so that IO,O००:I dilution yields $I_{\text {spmix }}=\mathrm{I} 2$, O०O sec.

\section{Subsystems Required}

The thrust/mass ratio attainable in the DFP system is determined by the masses of all of the subsystems of the complete engine system. First of these is the EXL/IEF unit, consisting of the magnet coils, e-guns and power supplies, cryogenic cooling and limiter vacuum systems, fuel feeds, and support structures. These must be driven by electrical power provided by the DCS, which includes the grids and standoff structures, and current leads to the IEF loads (e-guns and magnets). The propulsion thrust subsystem is based on the external (to the IEF unit) plasma confinement/thrust shell. This is toroidal, with super-conducting current carriers to provide the toroidal field that confines the diluent ions and fusion products until they reach some measure of energy equilibration. It also includes the propellant/diluent feed system and pumps and associated support structures. Finally, the mass of the waste heat radiator must be included. Figure 3, previously, gives the arrangement of 
subsystems in the DFP engine, and Figure 4 shows the current paths and resulting $B$ field distributions in the engine system external to the IEF unit.

\section{IEF Unit and}

\section{Toroidal Confinement Shell}

The mass of the IEF unit is determined by its magnet coils at radius $R$. Other masses of note are those of the e-guns, ion supplies, and support structures to hold the unit in place within the external shell. The magnet mass is determined by its volume, and this is set by the crosssection required for the current for the $B$ fields. In turn, this depends on the current density $\left(K_{a}\right.$, amps $\left./ \mathrm{cm}^{2}\right)$ that can be used by the cpo; superconductors. For coils at $K_{a}$ $=50 \mathrm{kA} / \mathrm{cm}^{2}$ with $B$ field of $13.5 \mathrm{kG}$, as before, the coil mass is $22,230 \mathrm{~kg}$ on a radius of $R=5 \mathrm{~m}$. The coil current is $15.3 \mathrm{MA}$ ( $\left.\mathrm{r}_{53} \mathrm{E}_{7} \mathrm{amps}\right)$.

The external thrust shell, which is spherical, embodies two structures; the superconductors that carry current to generate the outer section of the toroidal magnetic field, and a thin, spherical skin of high-strength steel to carry the magnetic pressure load of these conductors. The fields insulate the shell from impact by the fusion products and heated propellant/diluent ions. The DFP system used 360 conductors running longitudinally on the outside of the steel shell, each carrying $42.5 \mathrm{kA}$ and contained in cryogenically cooled steel tubes. These superconductors converge as they approach the torus axis, and close the current loop through paraxial conicallyarranged conductors that connect from the shell surface radius to the IEF main coil feed system, through the DCS structure. These conical conductor sets (one at each end of the torus axis) support the IEF and bound the DCS volume at each end of this support system. The total mass of the conductors on the shell and return cones (exclusive of IEF coils) is II,470 kg.

Designing the electrical/magnetic system so that the same current is used for both the IEF $B$ field coils and the shell superconductors gives a $B$ field at the mean shell radius of about $8.2 \mathrm{kG}$, and a surface field of 4.I kG. The gyro radius of fusion alphas is only about $12.2 \mathrm{~cm}$ at this shell mean radial field. Thus, the IEF-to-shell spacing is ca $4 \mathrm{I}$ gyro radii at fusion energies, allowing about I700 effective energy exchange collisions before permitting alphas to reach the wall; far greater collisionality than needed to equilibrate the alphas with the propellant. Figure 4 shows the arrangement of current paths and resulting $B$ fields.

\section{Plasma Exhaust Flow and Engine Thrust}

Propellant exhaust is ejected from the thrust shell through an exit hole on the shell equator. This "nozzle" is formed by external field coils that create a "bundle divertor" for confined plasma ${ }^{13}$ (Gross, 1984). Mass flow from this exit hole is the product of plasma density $n_{i}$ at the exit surface, the ion mass $m_{i}$, the exit speed (0.707 $\left.v_{i}\right)$, and the hole area $A_{e x}$. Multiplying this by the average exit speed yields the system thrust, and the thrust times the speed is just the system power. Finally the relationship between exit plasma density and the toroidal $\mathrm{B}$ field is found from the pressure balance $p=n E=\beta B^{2} /$ $8 \pi$, where $\beta$ is the plasma "beta" parameter (the ratio of kinetic to magnetic pressure at the exit plane).

\section{Current Flow and Toroidal B Field}

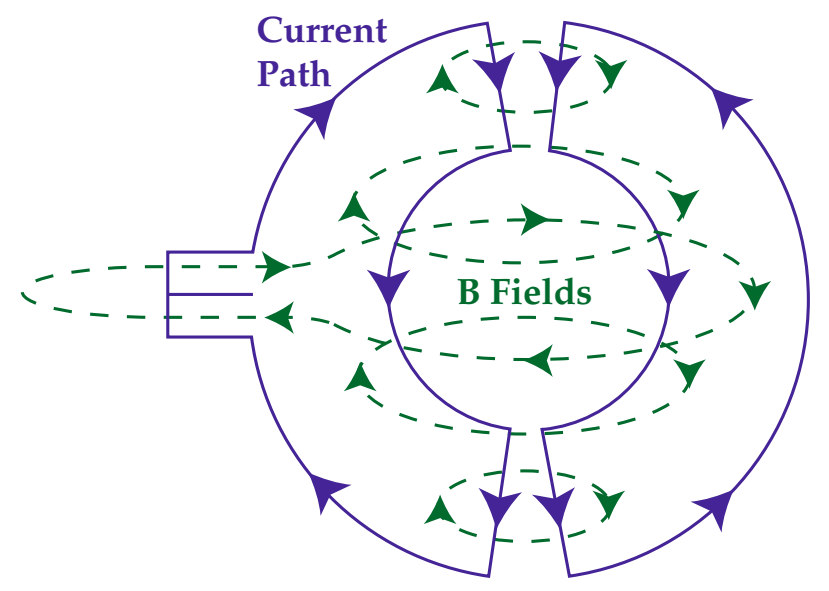

Current Flow and Toroidal B Field Configuration Figure 4 - DFP Engine Current and B Field Configuration

Combining all of these yields an equation for the size of exit hole required as a function of system power, fusion alpha particle energy, diluent mass flow mixture ratio $(D)$, plasma $\beta$, and the surface $B$ field $B_{e x}$. This equation incorporates all of the relevant physics inter relationships of the system and is:

$$
A_{e x}=1.04 \sqrt{\frac{D}{E_{\alpha}}}\left(\frac{P_{f u s}}{\beta B_{e x}^{2}}\right)_{(\mathrm{I})}
$$

Here the area is given in $\mathrm{cm}^{2}$ if $E_{\alpha}$ is alpha energy in $\mathrm{MeV}, P_{\text {fus }}$ is in MW, and $B_{e x}$ is in $\mathrm{kG}$ (kilogauss). As an example, consider a system with $P_{\text {fus }}=10,000 \mathrm{MW}, E_{\alpha}=$ ${ }_{4} \mathrm{MeV}$, with $D=25$ and a plasma beta of $\beta=0.03$ (typi- $^{-}$ cal). For these parameters the exit hole "nozzle" escape area will be $A_{e x}=0.867 \mathrm{E} 6 / B_{e x}{ }^{2} \mathrm{~cm}^{2}$. If $B_{e x}=4 . \mathrm{I} \mathrm{kG}$, as for the current flow conditions used above, this gives $A_{e x}=$ $5.156 \mathrm{E}_{4} \mathrm{~cm}^{2}$, for a hole radius of about I28.I cm., as shown in Figure 3. 


\section{Electrical Power Supply and IEF System Mounting}

The DCS mass is small because it is converting only about $2.4 \%$ of the total system power. With dual axialmounting, the acceptance hole area needed is $\mathrm{I} . \mathrm{I} \mathrm{m}$ in radius at the IEF boundary, and the standoff distance for the convertor grids can be less than $5 \mathrm{~m}$. The shell return current conductors carry the full magnet drive current through a conical conductor arrangement, delivering current to the distribution coil that feeds the main IEF coils. A similar arrangement takes the current out of the IEF magnets at the opposite end and returns it to the shell conductors. The IEF device is mounted so as to present a triangular face to the DCS units. This face area is about $6 \%$ of the total sphere area, thus each DCS free flow area fits well within the small dimensions of these triangular polyhedral faces. The IEF unit, itself, is supported from the edge of the DCS hole by the return current conductors, each carrying current to the e-guns and to the main coils from the electric power system supplied by the DCS. Three additional structural col$^{-}$ umns carry the $\mathrm{p}^{\mathrm{II}} \mathrm{B}$ fuel gas (as diborane, $\mathrm{B}_{2} \mathrm{H}_{6}$ ) to the gas injection system that fuels the unit.. Other supports are associated with the placement of the e-guns on each of the main (square) faces. These are mounted on radial spokes extending from the surface shell support structure. Estimates give $2290 \mathrm{~kg}$ for the mass of the $\mathrm{com}^{-}$ plete electric system, including dual power conditioning and DCS structures.

\section{Waste Heat Radiator and Cryogenic Cooling System}

A space radiator capable of handling $245 \mathrm{MW}$ of radiated power is required to dispose of the 22I MW of electrical drive power and $24 \mathrm{Mw}$ of unconverted particle power in the DCS. Since the radiator mass is just the product of its area $A_{r a d}$ and its specific area density $P_{r a d}$, its mass is fixed by the choice of radiating temperature, for any given emissivity. Using the usual radiation formulas $P_{\text {rad }}=\varepsilon \sigma T_{\text {rad }}$, where ( $\sigma$ is the Stefan-Boltzmann radiation constant $\left(5_{16}{ }_{7} \mathrm{E}-\mathrm{I} 2 \mathrm{w} / \mathrm{cm}^{2} \mathrm{~K} 4\right)$, and a specific mass of $3 \mathrm{~kg} / \mathrm{m}^{2}$ (single-sided) while allowing double-sided radiation, and taking a radiator temperature of $1050 \mathrm{~K}$, the radiator mass of the example DFP engine system is found to be only $5290 \mathrm{~kg}$.

Similarly, taking 70 watts of electric drive power as required for each watt of cryogenic cooling power, and limiting this to the unavoidable minimum due to gamma- and X-ray heating of the superconductor coils and conductors, it is found that the total cryogenic heat load is about $50 \mathrm{kWth}$. For this, the cryogenic system drive power must be about 3.5 MWe, all of which must be dumped to space via a radiator system. By analogy with the main space radiators, above, the cryogenic system radiators will have about $800 \mathrm{~kg}$ mass. The cryogenic pump mass is estimated to be $1600 \mathrm{~kg}$, and its power supply is taken at $0.5 \mathrm{~kg} / \mathrm{kWe}$ as $1750 \mathrm{~kg}$, for a cryogenic system hardware mass of about $4150 \mathrm{~kg}$. The complete system must also include fluids stored and used over its life; this is estimated to be about $350 \mathrm{~kg}$, for a total mass of $4500 \mathrm{~kg}$.

Other masses include the six e-guns, estimated at 840 $\mathrm{kg}$; the propellant/diluent $\left(\mathrm{LH}_{2}\right)$ supply pump system estimated at $500 \mathrm{~kg}$; and the $\mathrm{p}^{\text {II }} \mathrm{B}$ fueling system, including pumps, ion guns/injectors, and limiters, taken as $1000 \mathrm{~kg}$. These and all the other system masses are summarized in Table I.

\section{Table 1 - System/Subsystem Masses for DFP Fusion Rocket Propulsion Engine}

\begin{tabular}{|c|c|c|}
\hline Subsystem & $\begin{array}{c}\text { Estimated } \\
\text { Mass }\end{array}$ & Comment \\
\hline Radiator, $m_{\text {rad }}$ & $5,290 \mathrm{~kg}$ & $3 \mathrm{~kg} / \mathrm{m}^{2} ; 1050 \mathrm{~K}$ \\
\hline Misc., $m_{\text {misc }}$ & $\mathrm{I}, 320 \mathrm{~kg}$ & \\
\hline $\begin{array}{l}\text { Cryo. cooling } \\
\text { system, } m_{c r y o}\end{array}$ & $4,500 \mathrm{~kg}$ & 70W/cryo-W \\
\hline Shell, $m_{s h}$ & $2,950 \mathrm{~kg}$ & 4.I kG B fld \\
\hline Engine $\mathrm{S} / \mathrm{C}, m_{s c}$ & $\mathrm{II}, 470 \mathrm{~kg}$ & At $50 \mathrm{kA} / \mathrm{cm}^{2}$ \\
\hline $\begin{array}{l}\text { IEF } B \text { field coils, } \\
m_{\text {ief }}\end{array}$ & $22,230 \mathrm{~kg}$ & At $50 \mathrm{kA} / \mathrm{cm}^{2}$ \\
\hline $\begin{array}{l}\text { Fusion fuel sys- } \\
\text { tem, } m_{p B}\end{array}$ & $\mathrm{I}, 000 \mathrm{~kg}$ & \\
\hline $\begin{array}{l}\text { Diluent system, } \\
m_{L H}\end{array}$ & $500 \mathrm{~kg}$ & \\
\hline $\begin{array}{l}\text { Electric power } \\
\text { system, } m_{\text {elec }}\end{array}$ & $2,290 \mathrm{~kg}$ & At ro kg/MWe \\
\hline e-guns, $m_{e g}$ & $840 \mathrm{~kg}$ & $6 @ \mathrm{I} 40 \mathrm{~kg}$ \\
\hline Total, $m_{e}=m_{d} d f p$ & $52,390 \mathrm{~kg}$ & \\
\hline
\end{tabular}

\section{Vehicle Flight Performance}

Practical construction of a single-stage space vehicle requires that its dry mass be at least as large as about I/e of its full mass. Such a vehicle will give a characteristic 
velocity change increment during powered flight of $\delta v_{c}$ $=g I_{s p}$. Larger total flight velocity increment can be achieved only by use of:

(a) Successive stages, each providing another $\delta v_{c}$ from its own propulsive action, or

(b) Vehicles built with considerably less sturdy structure, i.e. with much less than I/e as dry mass fraction.

But:

(a) Multi-stage vehicles compound the overall vehicle system mass-ratio in an exponential fashion. Thus, systems beyond one stage rapidly become unattractive due to the extreme mass growth required to attain flight speeds markedly in excess of the "characteristic" speed set by $g I_{s p}$. And,

(b) Systems with flimsy construction are prone to failure and are unreliable, and are therefore unattractive for human space flight.

For these reasons, interest here is restricted to singlestage, I/e vehicles only. This limits flight to missions that can be accomplished within the range of $\delta v_{c}=g I_{s p}$ values attainable with the DFP engine.

\section{DFP Engine System Specific Impulse}

As discussed previously, the maximum $I_{s p}$ possible from the DFP engine is about I.2E6 sec for expulsion of the fusion product alphas, alone, with a sine ${ }^{2}$ angular distribution at the engine diverter exhaust plane. A lower limit also exists, set by the maximum plasma density that can be sustained within the confinement/thrust shell with tractable engine $B$ fields and maximum allowable plasma densities external to the IEF unit. This is about at a dilution ratio of $D=200$ or so; larger dilution gives higher thrust and lower $I_{s p}$ but may begin to affect IEF operation. Thus the useful and interesting range of dilution ratios in the DFP engine is $\mathrm{I}<D<200$. For the range of $D$ just given, the resulting range of $I_{s p}$ is $\mathrm{I} .2 \mathrm{E} 6>$ $I_{s p}>{ }_{7} \mathrm{E}_{4} \mathrm{sec}$, thus the corresponding range of useful single-stage mission flight velocities is $\mathrm{I}_{2} \mathrm{E}_{9}>\delta v_{c}>{ }_{7} \mathrm{E}_{7}$ $\mathrm{cm} / \mathrm{sec}$ or from $700^{-} \mathrm{I} 2,000 \mathrm{~km} / \mathrm{sec}$. Since one Astronomical Unit (AU) is about $\mathrm{I} .5 \mathrm{Er} 3 \mathrm{~cm}$ and there are $3.15 \mathrm{E}_{7}$ seconds/year, this velocity range is equivalent to a speed of $147^{-2520} \mathrm{AU} / \mathrm{year}$. It is clear from this that the DFP engine offers promise for both rapid transit missions to the Outer Planets (OP) and for distant substellar missions.

\section{Continuously Accelerating Flight}

The performance of DFP flight systems can be analyzed simply, by noting that the engine system power will be constant at its maximum value in any optimum operation. Furthermore, although minimum time trajectories may be constructed with variable $I_{s p}$ and constant power, it is always found that maximum payload or dry mass fraction is attained, for any given flight speed increment, by use of maximum $I_{s p}$ throughout the flight. Flight times with these engines are so short, for all missions of interest, that minimizing flight time is not of most importance. Rather, it is important to maximize payload capacity/fraction. Thus, flight analyses can be made on the basis of fixed power and fixed specific impulse. For these conditions, propellant consumption rate and engine thrust are fixed throughout the flight. Assuming that the flight profile is in field-free space then allows ready integration of Newton's equations for particle motion under constant force with changing acceleration.

For a rocket vehicle with propellant mass fraction $m_{p} /$ $m_{o}$ equal to $\mathrm{I}-(\mathrm{I} / \mathrm{e})=0.632$ at start of flight, the vehicle final speed (or characteristic velocity increment) will be $g I_{s p}=v_{e}$, the exhaust velocity of the propellant. Given fixed engine power and constant $I_{s p}$, the flight time during engine operation will be $t_{b}=\left(g I_{s p} / a_{0}\right)\left(m_{p} / m_{0}\right)=$ $0.632\left(g I_{s p} / a_{0}\right)$, where $a_{0}$ is the initial force acceleration of the full vehicle. Similarly, flight distance under thrusting power is found to be $s_{b}=\left(v_{e}^{2} / a_{0}\right)\left(\mathrm{I}^{-2} / \mathrm{e}\right)=0.264\left(v_{e}^{2} / a_{0}\right)$. To assess actual performance for any desired $I_{s p}$ it is thus necessary to choose a vehicle initial mass and engine power (or ratio of power to mass; noting that $a_{0}=2 P_{f u s}$ l $\left.m_{0} g^{2} I_{s p}\right)$. For illustrative purposes take $P_{f u s}=10,000 \mathrm{MW}$, as previously discussed for the example DFP $\mathrm{p}^{\text {II }} \mathrm{B}$ engine system (burns $0.144 \mathrm{gm} / \mathrm{sec}$ of $\mathrm{p}^{\mathrm{II} B}$ ), and assume that $m_{0}$ $=400,000 \mathrm{~kg}$. Then flight performance for various $I_{s p}$ values will be as shown in Table 2 , following. 
Table 2 - Summary of Accelerating QIS Flights with DFP Engines

\begin{tabular}{|c|c|c|c|c|c|}
\hline Parameter & \multicolumn{4}{|c|}{ Value } & Units \\
\hline & \multicolumn{4}{|c|}{ All Flight Profiles } & \\
\hline$I_{s p}$ & $\mathrm{IE}+\mathrm{O} 6$ & $3 \mathrm{E}+05$ & $2 \mathrm{E}+05$ & $\mathrm{IE}+05$ & sec \\
\hline$D$ & 0.44 & 15.0 & $35 \cdot 0$ & I43 & \\
\hline$F$ & 200 & 667 & 1000 & 2000 & $\mathrm{~kg}$ \\
\hline$a_{0}$ & 0.5 & I.667 & 2.5 & 5.0 & $\mathrm{~cm} / \mathrm{sec} 2$ \\
\hline$d m_{p} / d t$ & 0.2 & 2.22 & 5.0 & 20 & $\mathrm{gm} / \mathrm{sec}$ \\
\hline \multirow[t]{2}{*}{$m_{\text {fuel }}$} & I81.6 & I6.35 & 7.26 & I. 82 & $\mathrm{~T}$ \\
\hline & \multicolumn{4}{|c|}{ Continuously-Accelerating Flight Profile } & \\
\hline$t_{b}$ & 4O.I & 3.6I & I.605 & $0.40 \mathrm{I}$ & year \\
\hline$s_{b}$ & $35,200(.56 \mathrm{LY})$ & $95 \mathrm{I}$ & 281. 8 & 35.2 & $\mathrm{AU}$ \\
\hline$v_{b}=v_{e}$ & 2100 & 630 & 420 & 210 & AU/year \\
\hline$g I_{s p}$ & $\mathrm{c} / 30$ & 3000 & 2000 & 1000 & $\mathrm{~km} / \mathrm{sec}$ \\
\hline
\end{tabular}

From this, note how rapidly the flight "burn" time changes with $I_{s p}$, as does the $\mathrm{p}^{\text {II B }}$ fuel consumed, and the distance traversed in powered flight. Note, also, that even though this example is only of a single-stage (I/e) vehicle, the highest $I_{s p}$ version is nearly (but not quite) a starship, covering a distance of 0.56 lightyears (LY) in its thrusting time of 4 O.I years. This really astonishing performance is a direct result of the extremely high power/ mass ratio of the DFP engine, and of its use of fusion products to provide thrust through the medium of the toroidal-field constrained thrust shell of the DFP system. However, the vehicles in these examples are moving at maximum speed at propellant burnout, thus they are impractical for flights involving human crews or scientific payloads for emplacement at distant points.

\section{Acceleration / Coast / Deceleration Flight}

Of greater interest are missions in which the vehicle is accelerated to half of its total velocity increment capability, coasts a portion of the flight distance, and then decelerates to zero space-frame speed once again, so that its payloads can be disembarked at a pre-chosen point in space. Analysis of such acceleration / coast / deceleration flights is somewhat more tedious than for the simple acceleration profiles of Table 2, but still straightforward because of the unique optimal operational conditions for the DFP engine. Following the previous arguments, integration of Newton's force equations gives simple formulas for flight time and distance during the acceleration and deceleration phases of flight. These are:

\begin{tabular}{|l|l|l|}
\hline Acceleration & $\begin{array}{l}s_{b_{1}}=0.0902\left(v_{e}^{2}\right. \\
\left.a_{0}\right)\end{array}$ & $\begin{array}{l}t_{b I}=0.3935 \\
\left(v_{e} / a_{0}\right)\end{array}$ \\
\hline Flight & $m_{p l}=0.3935 m_{0}$ & $m_{b l}=0.6065 m_{0}$ \\
\hline Coast & \multicolumn{2}{|c|}{$v_{\text {coast }}=\left(\frac{v_{e}}{2}\right)=\left(\frac{g I_{s p}}{2}\right)$} \\
\hline Deceleration & $\begin{array}{l}s_{b_{2}}=0.06465\left(v_{e}^{2}\right) \\
\left.a_{0}\right)\end{array}$ & $\begin{array}{l}t_{b_{2}}=0.2387\left(v_{e} /\right. \\
\left.a_{0}\right)\end{array}$ \\
\hline Flight & $m_{p_{2}}=0.2387 m_{0}$ & $m_{b_{2}}=0.3678 m_{0}$ \\
\hline
\end{tabular}

Using these formulae, flight performance can be assessed for any mission distance and any given choice of specific impulse. Note that, for any possible mission 
there will always be an optimum $I_{s p}$ which will give the least transit time This can be found only by use of the formulae, above, for the specified mission. For example, earlier studies showed ${ }^{\text {Io }}$ that flight to 557.4 AU (the Oort cloud) could be accomplished in a minimum time of about 3.3 years at an $I_{s p}$ of approximately $2 \mathrm{E}_{5} \mathrm{sec}$.

This vehicle system had a dilution ratio of $D=35$. 0 , thus its propellant mass was largely diluent (hydrogen, water, or ammonia), and its structure mass principally that of propellant tankage. With the small vehicle accelerations used (o.oIg = IO cm/ $/ \mathrm{sec}^{2}$, or so), this was assumed conservatively to be Io\% of the propellant mass. Then the mass distribution of this example vehicle system was $m_{o}$ $=400,000 \mathrm{~kg}$ as gross mass, propellant mass was $m_{p}=$ $252,800 \mathrm{~kg}$, of which $m_{p B}=7,260 \mathrm{~kg}$ was $\mathrm{p}^{\text {II B fusion fuel }}$ and $m_{H}=245,240 \mathrm{~kg}$ was propellant/diluent. Tankage and associated structure was found to be $m_{s t r}=25,280$ $\mathrm{kg}, m_{e}=5 \mathrm{I}, 705 \mathrm{~kg}$ was DFP engine mass, leaving $m_{L}=$ $70,215 \mathrm{~kg}$, or $17.6 \%$ for payload, guidance, electronics, instruments, etc. This is a very high payload fraction for a single-stage vehicle on such a mission, and illustrates the very great potential of the DFP engine.

\section{Titan Colony Mission}

An example mission of much greater illustrative value for near-term use of the DFP engine system, is that of travel to and colonization of Titan, the largest moon of Saturn. This body is believed to have ice (and thus water) on its surface; it is larger than Earth's moon, and has a larger surface gravity, being about $\mathrm{I} / 5$ that of Earth. It is sufficiently far from Saturn that its orbit is not prohibitively deep into Saturn's gravitational well. Thus it is accessible to ultra-fast deep-space vehicles with high delta-vee capabilities, without significant propulsion and payload penalties. However, in order to accomplish such a colonization mission over a reasonable period of time - e.g. ten years - the vehicle propulsion system used must be able to provide transit times measured in tens of days, rather than in tens of years.

\section{Mission Characteristics}

The orbit of Saturn varies from 9-Io AU from the Sun, thus its distance from the Earth may vary from 8-II AU, depending on whether it is in opposition or conjunction with the Earth. Average flight speeds needed are then in the range of Io AU per Ioo days, or $15 \mathrm{Mkm}$ /day or 200 $\mathrm{km} / \mathrm{sec}$, for example. Such average speeds imply four times this for vehicle characteristic velocity for an acceleration-coast-deceleration flight profile, thus vehicle characteristic velocity capability must be in the range of $\delta V_{c}=800 \mathrm{~km} / \mathrm{sec}$, or $I_{s p}=80,000 \mathrm{sec}$, a truly stunning value by present standards. Using the Newtonian formulae just given, the $I_{s p}$ required for no-coast flight to Titan ranges from 72,500 sec to 80,700 sec for transits over 8.o AU (closest approach) to Ir.o AU(most distant path). A specific impulse value of $I_{s p}=70$, 000 sec was used for the analysis, thus all mission flight profiles had midcourse coast flight segments.

The Earth to Titan transfer vehicle using this DFP engine would leave from LEO and travel to a low orbit about Titan (LTO). Its thrust is too small to allow direct surface landing; thus some form of LTO/T shuttle is required to offload passengers and payload to the Titan surface. However, the low surface gravity of Titan allows a T/LTO shuttle of only modest $\delta v$ capability, as compared to that required for $\mathrm{E} / \mathrm{LEO}$, for example. The $\mathrm{LEO} / \mathrm{L} \mathrm{TO}$ transfer vehicle loaded gross mass in LEO is taken to be $400 \mathrm{~T}{ }^{11}$, with an engine system mass of $52 \mathrm{~T}$ (as above), $252 \mathrm{~T}$ of propellant, $25 \mathrm{~T}$ for fixed crew and habitat quarters and associated life support systems, and $26 \mathrm{~T}$ for structure (propellant tankage, etc). The remainder is useful payload of $45 \mathrm{~T}$. The vehicle outline is shown in the sketch given in Figure 5, following:

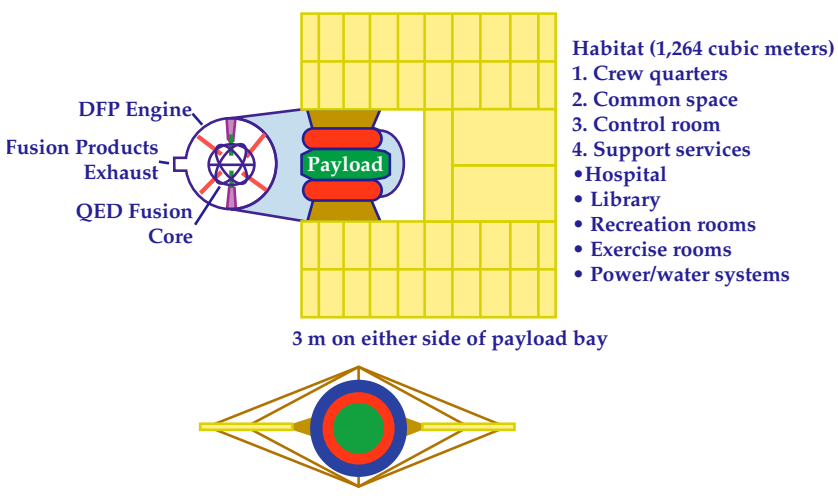

Figure 5 - Schematic Outline of LEO/LTO Transfer Vehicle

With these masses, the vehicle speed at the end of the initial thrusting phase is found to be $343.2 \mathrm{~km} / \mathrm{sec}$, or 0.2 AU/day. Additional vehicle energy required for capture into Titan's orbit around Saturn and into low orbit around Titan must be added at this point in the flight. Since escape from Saturn at Titan's orbital distance requires $8077 \mathrm{~m} / \mathrm{sec}$ and escape from Titan's surface needs $2990 \mathrm{~m} / \mathrm{sec}$, the total velocity increment needed at Titan is $11,067 \mathrm{~m} / \mathrm{sec}$, or about II.I $\mathrm{km} / \mathrm{sec}$. Because of the very high speed at mid-course of $343.2 \mathrm{~km} / \mathrm{sec}$, the energy addition can be made here with a velocity increment of $\left[(343.2)^{2}+(\mathrm{II} . \mathrm{I})^{2}\right]^{0} \cdot 5=\mathrm{I} 73 \mathrm{~m} / \mathrm{sec}$; which requires about $\mathrm{I} 25$ $\mathrm{kg}$ of additional propellant. This is trivial and ignorable as compared to the rest of the flight requirement.

\section{Mission Parameters and Economics Estimates}

For this mission, it was assumed that an on-ground colony of 400 people would be established on Titan over a period of Io years, with recycle rotation back to Earth allowed for each colonist, once every year. With the 
chosen specific impulse, the transit times for $\mathrm{E} / \mathrm{T}$ flight are in the range of 75 to 90 days, or 2.5-3 months for each OW trip. Personnel recycle then requires 5-6 months, and LEO/LTO vehicle flight usage can not practically exceed I.5 RT per year. Allowing 6 months on Earth for rotational leave then gives only a $50 \%$ duty factor for Titan-based personnel.

With this assumption 400 people must be in transit or on Earth at any one time after establishment of the 400 person on-ground Titan colony. While the colony is being established the personnel interplanetary transfer rate is about twice the on-ground population count, but the transport rate of capital plant and equipment to set up the colony is just that required for the 400 colony staff personnel on the ground. For cost estimation, it was assumed that 60 T of capital plant and equipment, and an expendable mass of $2000 \mathrm{~kg} /$ person is carried on each transfer flight. E/LEO transport costs are taken at $\$ 27.0 / \mathrm{kg}$, from earlier studies, and $\$ 24.2 / \mathrm{kg}$ is allowed for low Titan satellite orbit to ground (LTO/T) transport delivery. The dominant cost is that of LEO/LTO transport; this has been estimated at $\$ 28 \mathrm{o} / \mathrm{kg}$, excluding any financial costs, but with operations and maintenance $(\mathrm{O} \& \mathrm{M})$ costs taken at $2 \%$ per flight over Ioo flights per vehicle. These economic and cost assumptions and conditions have been discussed in more detail previously ${ }^{8, \mathrm{II}, \mathrm{I} 2}$. Under these conditions the total cost rate for this mission becomes:

$$
\frac{d C_{0}}{d Y}=1.235 \times 10^{9}+0.772 \times 10^{8} Y(\$ / \text { year })
$$

from which the integrated cost over the desired $\mathrm{Y}=\mathrm{IO}$ year period is found to be $C_{0}(\mathrm{IO})=\$ 1 \mathrm{I} 6.2 \mathrm{IE} 9=\$ \mathrm{I} 6.2 \mathrm{IB}$ for OW delivery of a 400 person colony to Titan, with 24,000 metric T of capital plant together with supporting facilities. housing, life support, medical, communications, et al, and transfer vehicle maintenance and refueling equipment. True round-trip costing requires knowledge of market value on Earth of material transported back from Titan, or from other points in the outer solar system. Certainly such vehicles could be used to mine the asteroids, to move small asteroids, establish colonies on the moons of Jupiter, etc, whose potential future value is yet difficult to estimate.

\section{Summary and Conclusions}

Previous studies of DFP engine system performance have analyzed two other Colony mission; one to put 4000 people on the Moon, and another to establish I200 people on Mars, each with 25 to 50 T per person, respectively, of installed infrastructure. Total costs of these three Colony missions were found to be about $\$ 45$ $\mathrm{B}$ for their completion over a ten year period, for a total cost less than $\mathrm{I} / 3$ of the NASA annual budget over this time. Once established these could become selfsupporting and engage in expansion of their own, again using DFP engine systems.

The value of such colonies is almost impossible to quantify at present. The only model available for such guesstimates is that facing Columbus when he first set sail for what was to prove to be North America. History has shown that the visions of his sponsors and contemporaries were woefully inadequate to project the future value of the civilizations, industries, knowledge and ideas that would grow in this new environment. Would space colonization be expected to be any less important or valuable? The DFP engine systems offer almost the only means presently seen to carry out such ventures. Their development and use will give us the tools to find the answers to these questions, which can be found only by human expansion into the interplanetary frontiers of our Solar System.

\section{Revision History}

Copyright 200 i by Robert W. Bussard. Published by permission by the American Institute of Physics (AIP) Conference Proceedings - January I4, 2002 - Volume 6o8, pp. 768-779, Space Technology and Applications International Forum.

Reformatted and color illustrations added August 2007 by Mark Duncan. References updated April 2009. 


\section{References}

${ }^{\text {I }}$ Robert W. Bussard and Richard D. DeLauer; Nuclear Rocket Propulsion, McGraw-Hill Book Co., NY, 1958.

2 Maxwell Hunter; "Solar System Spaceships," Thrust Into Space, Holt, Rhinehart \& Winston, NY, 1966, Chapter 5 .

3 Robert W. Bussard and Richard D. DeLauer; Fundamentals of Nuclear Flight, McGraw-Hill Book Co., NY, 1965.

4 Robert W. Bussard; "ASPEN-IT: Two-Staging and Radiation Shielding Effects On ASPEN Vehicle Performance," LA-2680, 6nS/62, declassified with deletions 9/6/ 1967; and in "ASPEN: Nuclear Propulsion for Earth-toOrbit Aerospace Plane Vehicles," RW. Bussard, Proceedings International Conference on Spaceflight, Rome, June I97I.

5 Robert W. Bussard; "Method and Apparatus For Controlling Charged Particles," U.S. Pat 4,826,626, 5/2/1989, and "Physics Considerations of Magnetic-InertialElectrostatic Confinement - A New Concept for Spherical Converging-Flow Fusion, Fusion Technology, vi9, March I991, 273.

${ }^{6}$ Nicholas A. Krall; "The Polywell: A SphericallyConvergent Ion Focus Concept," Fusion Technology, volume 22, August 1992, p. 42.

7 John F. Santarius; "Magnetic Fusion Energy and Space Development," Proceedings 24th Intersociety Energy Conversion Conference, IEEE, v5, I989, pp 2525.

${ }^{8}$ Robert W. Bussard; "The QED Engine System: DirectElectric Fusion-Powered Rocket Propulsion Systems," Paper \#263, Proceedings ioth Symposium on Space/Nuclear Power and Propulsion, Albuquerque, NM, IO-I4 January 1993.

9 Robert W. Bussard and Lorin W. Jameson; “The QED Engine Spectrum: Fusion-Electric Propulsion for Air Breathing to Interstellar Flight," AIAA paper 93-2006, 29th Joint Propulsion Conference, Monterey, CA 6/2830/ 1993; Fournal of Propulsion and Power, viI, n2, pp. 365/ 372.

Io Robert W. Bussard, Lorin W. Jameson and H.D. Froning, Jr.; "The QED Engine: Fusion-Electric Propulsion for Cis-Oort/Quasi-Interstellar Flight," Proceedings of the 44th Congress at the International Astronautical Federation, IO/22/1993, Graz, Austria.
II Robert W. Bussard; "System Technical and Economic Features of QED-engine-Driven Space Transportation," AJAA-97-3071, paper given at 33rd AIAA/SAE/ASME/ ASEE foint Propulsion Conference, Seattle, WA, 6-9 July 1997.

I2 Robert W. Bussard and H.D. Froning; "System/ SubSystem Engineering Interface Considerations and R\&D Requirements for IEF /QEDd Engine Systems," Paper \#232, Section F, STAlF-98, 15th Proceedings of Space Technology and Applications International Forum, Albuquerque, NM, 25-29 January 1998.

13 Robert A. Gross; "Fusion Energy," John Wiley \& Sons, Inc., NY, 1984, p. $134 \mathrm{ff}$. 